\title{
Stroke-unit care for acute stroke patients: an observational follow-up study
}

Livia Candelise, Monica Gattinoni, Anna Bersano, Giuseppe Micieli, Roberto Sterzi, Alberto Morabito, on the behalf of the PROSIT Study Group

\begin{abstract}
Summary
Background Large numbers of stroke patients arrive at hospital at a very early stage, and effective treatments for the acute phase of the disease are available. However, evidence that patients with acute stroke benefit from stroke-unit care is scarce. Our aim was to determine whether admission to a stroke unit, rather than a conventional ward, affected the outcome of patients with acute stroke.
\end{abstract}

Methods We did an observational follow-up study of 11572 acute stroke patients hospitalised within $48 \mathrm{~h}$ of the onset of symptoms either in a stroke unit $(n=4936)$ or in a conventional ward (6636). Patients were identified retrospectively from discharge records from 260 Italian hospitals. The primary outcome was mortality or disability (Rankin score greater than two), assessed prospectively by independent, masked assessors 2 years after admission. Analyses were adjusted for patient characteristics and clustered at the hospital level.

Findings Overall, 1576 patients died in hospital; 2169 died during the follow-up period. 347 patients were lost to follow-up. Compared with conventional-ward care, stroke-unit care was associated with a reduced probability of death or being disabled at the end of follow-up (odds ratio $0 \cdot 81,95 \% \mathrm{CI} 0 \cdot 72-0 \cdot 91 ; \mathrm{p}=0 \cdot 0001$ ). The potential benefit was significant across all age ranges and clinical characteristics, except for unconsciousness. No specific elements of setting, organisation, or process of care were associated with outcome.

Interpretation Admission to a stroke-unit ward with dedicated beds and staff within $48 \mathrm{~h}$ of onset should be recommended for all patients with acute stroke.

\section{Introduction}

Several randomised controlled trials have been done in different countries and environments to assess the effectiveness of stroke-unit care for hospitalised stroke patients. ${ }^{1}$ The results of these studies were combined in a Cochrane systematic review, which definitively showed the benefit of stroke-unit care. ${ }^{1}$ However, there is still some delay in implementation of stroke-unit wards in European countries. ${ }^{2}$ The large-scale applicability of some of the complex interventions that were used experimentally on small, selected groups of patients included in the randomised trials is debatable. Guidelines differ about important aspects of stroke care-eg, acuteness for admission, patient selection, and care organisation. ${ }^{3}$ In North America there is even disagreement on the need to have a discrete, dedicated ward together with a dedicated stroke team. ${ }^{4,5}$

The Italian National Ministry of Health has promoted a stroke-unit research project (Research Project on Stroke services in Italy, PROSIT) since 2000, which involves many institutions around the country. This project enabled us to do a large-scale controlled prospective trial to assess the effectiveness of stroke-unit care. Our aim was to determine whether all acute stroke patients admitted into stroke units have a better long-term outcome than those treated in conventional wards.

\section{Methods}

Participants and procedures

This study is an observational controlled follow-up study on acute stroke patients, done in hospitals in Italy between
2000 and 2004, to compare the long-term outcome of patients cared for in stroke units with those cared for in conventional wards. Seven Italian regions (Lombardia, Liguria, Veneto, Friuli-Venezia Giulia, Emilia-Romagna, Toscana, and Lazio), with a population of about 29 million and more than 50000 acute stroke discharges every year, took part in the study.

The study was done in accordance with guidelines for good clinical practice and the declaration of Helsinki. Central and local ethical committee approval was sought. A patient information standard procedure supported the patient consent process to use clinical data for research purposes. Oral consent was obtained by phone at the time of the follow-up telephone call.

We defined the stroke unit as a hospital ward with dedicated beds (at least $80 \%$ stroke admission) and with a dedicated stroke staff (at least one physician and one nurse) who work exclusively in the care of stroke patients. The conventional ward was defined as a hospital service with neither dedicated beds nor staff, in which stroke patients are cared for together with other patients (eg, neurological, internal medicine, cardiological). To identify stroke units and conventional wards, we audited the local hospital services of all regional hospital sites that had discharged at least 50 acute stroke patients in the previous year. We also gathered data on the service characteristics (setting, organisation, and process of care). The audit process terminated in February, 2001, and 31 stroke units and 393 conventional wards were identified. The details of
Lancet 2007; 369: 299-305

See Comment page 254

Dipartimento di Scienze Neurologiche, Ospedale Maggiore Policlinico IRCCS Università degli Studi di

Milano, Milan, Italy (Prof L Candelise MD, M Gattinoni PhD, A Bersano MD); Stroke Unit, Istituto Neurologico Mondino IRCCS, Pavia, Italy (G Micieli MD); SC Neurologia, Ospedale Niguarda Ca'Granda Milano, Milan, Italy (R Sterzi MD); and Cattedra di Statistica Medica, Facoltà di Medicina e Chirurgia, Università degli Studi di Milano, Milan, Italy (Prof A Morabito MD)

Correspondence to: Prof Livia Candelise, Dipartimento di Scienze Neurologiche, Università degli Studi di Milano, Ospedale Maggiore Policlinico, Via F Sforza, 35, 20122 Milano, Italy livia.candelise@unimi.it 
the data gathered during this phase of the study have been described previously. ${ }^{6,7}$

For ward characteristics, the major elements were dichotomised as follows: hospital setting (academic hospital, presence in the same hospital of intensive care, neurosurgery, vascular surgery, and rehabilitation departments), unit setting (all neurological beds, yearly unit admission more than 100 patients per year, continuous electrocardiography monitoring equipment more than two per ten beds), staffing per unit ward (number of full-time physicians, nurses, and therapists: more than 2,5 , and 0.5 per ten patients, respectively), diagnostic investigation (availability over $24 \mathrm{~h}, 7$ days a week, of cranial CT scan, brain MRI scan, echocardiography, duplex ultrasound, and cerebral catheter angiography), and process of care (declared use in the unit of written nurse care protocols, practice of multidisciplinary team meetings, and of early mobilisation).

Acute stroke patients were identified by the Discharge Related Group (DRG) 14 code. DRG 14 corresponds to ICD-9-CM 431, 432, 433, 434, 436, and 437 codes that have been shown to be highly specific for acute stroke. ${ }^{8}$ Ischaemic and haemorrhagic strokes were accepted. The diagnosis and the duration of symptoms (less than $48 \mathrm{~h}$ ) were confirmed by assessment of clinical records. We included all cases with acute stroke who were admitted during the last 9 months of 2001 in the 31 stroke units previously identified. Patients for whom clinical data were not available or those readmitted to the same service in 1 year were excluded. Controls were a sample selected with a computer-generated random numbers list stratified by regions of about $20 \%$ of acute stroke cases admitted in each of the 393 conventional wards during the same period. To avoid selection and performance bias, we
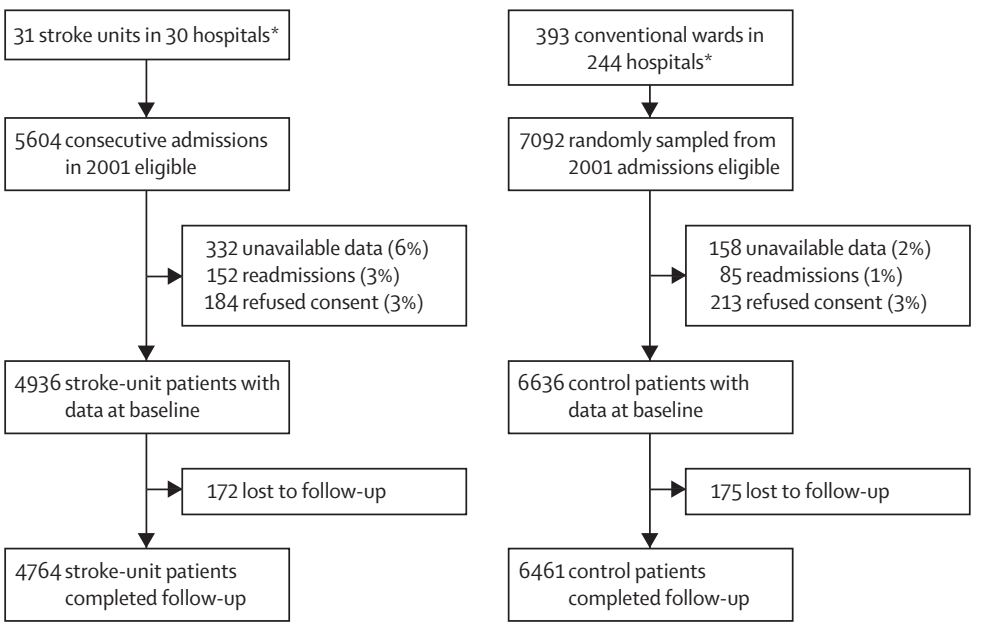

Figure 1: Trial profile

*14 hospitals had both stroke unit and conventional ward. included the patients admitted after finishing the auditing process described above.

16 trained independent clinicians reviewed patients clinical records blinded to the patient's hospital status. They confirmed diagnoses of acute stroke and recorded demographic, clinical, and in-hospital outcome data. The following baseline characteristics were recorded: age, male sex, admission time, intracranial haemorrhage at first CT scan, atrial fibrillation at first electrocardiograph, systolic and diastolic arterial blood pressure, unconsciousness (score less than 4 of eye opening on the Glasgow coma scale) and drift in at least one limb at motor assessment.

Follow-up assessments were done between 2002 and 2004 centrally for all regions. The assessors were an independent group of 21 medical students and four nurses trained to use a structured follow-up form, masked to the patient's hospital status. They registered the patients' vital status, place of residence, and functional ability with a modified Rankin scale. The modified Rankin scale graded the patients from grade 0 (no symptoms) to grade 5 (bedridden, incontinent, and requiring constant nursing care and attention). The inter-observer agreement and its use by telephone are reliable. ${ }^{9,10}$ If the patient was unwilling to answer the questions, information was obtained from a carer or proxy. About a third of patients-38\% of those receiving stroke-unit care and $32 \%$ of controls-completed the telephone interviews by themselves.

The primary outcome measure was death or dependency condition (ie, Rankin score higher than two) recorded at the time of long-term follow-up. Secondary outcomes were in-hospital case fatality, long-term mortality, and long-term living condition (ie, whether the patient was living at home or not) at follow-up.

\section{Statistical analysis}

We aimed to recruit a sample of about 10000 cases from about 200 hospitals, each admitting at least ten patients, which would have $80 \%$ power to detect an absolute risk difference of $6 \%$ (two sided $p=0 \cdot 05$ ) if $62 \%$ of those treated in a conventional ward were dead or had a poor outcome, to detect an absolute risk difference of $3 \%$ if $18 \%$ treated in conventional wards were dead at discharge, and to detect an absolute risk difference of 3\% if $29 \%$ treated in a conventional ward were not living at home at the long-term follow-up assessment. The sample size for hospital clusters was estimated assuming a coefficient of variation of $0 \cdot 22 .^{11}$

Hospitals' intra-cluster correlation coefficients were calculated for all baseline variables. ${ }^{12}$ The outcome analyses take into account all included cases. Cases lost to follow-up were counted in the denominators. To determine whether their inclusion affected the results, we did best-case and worst-case scenario analyses. The best-case scenario was analysed on the basis of the assumption that the patients who were lost to follow-up were alive and independent in the stroke-unit group and dead or disabled in the conventional ward group. We also 
did a worst-case scenario analysis on the basis of the assumption that the patients lost to follow-up in the stroke unit were dead or disabled and were alive and independent in the conventional ward group.

Multivariate analyses were done to assess the association between type of unit care and patient outcomes, adjusting for patient characteristics (age, sex, time from stroke onset, intracranial haemorrhage, atrial fibrillation, level of consciousness). All multivariate logistic regression models for the main and subgroup analyses were done with generalised estimating equations to account for clustering of predictor variables and outcomes at different hospital levels. To determine goodness-of-fit, the final model was assessed by Hosmer-Lemeshow test with ten risk intervals. For time-to-event outcomes, we used Cox regression survival analyses; hazard ratios were clustered at hospital level. Statistical analyses were done with Stata version 8.0.

\section{Role of the funding source}

The Italian National Ministry of Health and Lombardia Regional Health Department funded the study. The sponsors had no role in study design, data collection, data analysis, data interpretation or writing the report. The corresponding author had full access to all the data, and had final responsibility to submit for publication.

\section{Results}

Figure 1 shows the trial profile. At baseline, data were available for 11572 acute stroke patients from 424 units and 260 hospitals were studied. 16 hospitals had only stroke units and 230 only conventional wards; 14 hospitals had both types of ward. The number of cases for the three types of hospitals were 2502,6260 , and 2810 , respectively. Table 1 shows the baseline characteristics for these patients. $90 \%$ of baseline data were complete.

Table 2 presents data on the follow-up status of patients. 95\% of follow-up data were complete. 347 (3\%) patients were not found at the telephone number provided during hospitalisation, and it was not possible to trace them by asking the local municipal administrative office of declared residence. These individuals were thus lost to follow-up. These cases did not differ significantly from the included cases in terms of the characteristics of patients. The mean follow-up time was much the same for stroke units as it was control groups (19.7 [SD 6.9] months vs $20 \cdot 4$ [7.2] months). Overall, 1576 patients died in the hospital; 2169 (19\%) died during the follow-up period (table 2).

Patients who received stroke-unit care were less likely to be dead or disabled than the controls by the end of followup after adjusting for inter-hospital variability (OR 0.81, 95\% CI $0 \cdot 72-0 \cdot 91 ; \mathrm{p}=0 \cdot 0001$; table 3 ). Inclusion of those lost to follow-up did not affect our results; OR in the bestcase scenario was $0 \cdot 70$ (95\% CI 0.61-0.79), whereas in the worst-case scenario it was $0 \cdot 91(0 \cdot 82-0 \cdot 99)$. Comparison of the outcomes of patients admitted to hospitals with stroke units, irrespective of whether they were admitted to stroke unit or normal ward, with those of patients admitted to hospitals without such units showed much the same association $(0 \cdot 81,0 \cdot 71-0 \cdot 91 ; \mathrm{p}=0 \cdot 0001)$.

The possible benefit of stroke-unit care was also evident for in-hospital, long-term mortality, and for the likelihood of not being at home 2 years after hospital discharge (table 3). Survival of patients treated in stroke units was

\begin{tabular}{|lccc|}
\hline & $\begin{array}{l}\text { Patients in stroke } \\
\text { unit }(\mathbf{n = 4 9 3 6 )}\end{array}$ & $\begin{array}{l}\text { Patients in } \\
\text { control wards } \\
(\mathbf{n = 6 6 3 6 )}\end{array}$ & $\begin{array}{l}\text { Intra-class } \\
\text { correlation } \\
\text { coefficient }\end{array}$ \\
\hline Age (years) & $72(12 \cdot 9)$ & $76(12 \cdot 2)$ & 0.038 \\
\hline Men & $2590(52 \%)$ & $3195(47 \%)$ & 0.001 \\
\hline Admission within 6 $\mathrm{h}$ & $1926(39 \%)$ & $2526(36 \%)$ & 0.168 \\
\hline Intracranial haemorrhage & $412(7 \%)$ & $859(13 \%)$ & 0.214 \\
\hline Atrial fibrillation & $794(16 \%)$ & $1280(19 \%)$ & 0.034 \\
\hline Systolic blood pressure (mm Hg) & $159(28 \cdot 9)$ & $164(37 \cdot 4)$ & 0.022 \\
\hline Diastolic blood pressure (mm Hg) & $87(14 \cdot 4)$ & $90(14 \cdot 4)$ & 0.043 \\
\hline Unconsciousness & $675(13 \%)$ & $1303(20 \%)$ & 0.034 \\
Unconsciousness or motor impairment & $3297(70 \%)$ & $4576(69 \%)$ & 0.066 \\
\hline Aphasia & $1307(25 \%)$ & $1819(26 \%)$ & 0.042 \\
\hline Length of stay in hospital (days) & $12(11 \cdot 3)$ & $12(12 \cdot 2)$ & 0.070 \\
*Adjusted for hospital clusters. Data are mean (SD) or number (\%). & & \\
\hline Table 1: Distribution of baseline characteristics & & \\
\hline
\end{tabular}

\begin{tabular}{|c|c|c|}
\hline & Stroke unit $(n=4936)$ & Control $(n=6636)$ \\
\hline Follow-up (months) & $19 \cdot 7(6 \cdot 9)$ & $20 \cdot 4(7 \cdot 2)$ \\
\hline Lost to follow-up & $172(3 \%)$ & $175(3 \%)$ \\
\hline In-hospital case fatality & $542(11 \%)$ & $1034(16 \%)$ \\
\hline Death after discharge & $821(17 \%)$ & $1348(20 \%)$ \\
\hline Alive at follow-up & 3401 (69\%) & $4079(61 \%)$ \\
\hline Rankin score $=0^{*}$ & $735(22 \%)$ & $804(20 \%)$ \\
\hline Rankin score $=1^{*}$ & $871(26 \%)$ & $941(23 \%)$ \\
\hline Rankin score $=2^{*}$ & $547(16 \%)$ & $604(15 \%)$ \\
\hline Rankin score $=3^{*}$ & $590(17 \%)$ & 740 (18\%) \\
\hline Rankin score $=4^{*}$ & $471(14 \%)$ & $713(17 \%)$ \\
\hline Rankin score $=5^{*}$ & $187(5 \%)$ & $277(7 \%)$ \\
\hline Stroke recurrence & $195(4 \%)$ & $265(4 \%)$ \\
\hline Rehabilitation programme & $1089(22 \%)$ & $1381(21 \%)$ \\
\hline New hospital admissions & $835(17 \%)$ & $992(15 \%)$ \\
\hline \multicolumn{3}{|c|}{$\begin{array}{l}\text { Data are mean (SD) or number (\%). }{ }^{*} \text { Data are number (percentage of those alive at } \\
\text { follow-up). }\end{array}$} \\
\hline
\end{tabular}

\begin{tabular}{|c|c|c|c|c|}
\hline & $\begin{array}{l}\text { Stroke unit } \\
(n=4936)\end{array}$ & $\begin{array}{l}\text { Control } \\
(n=6636)\end{array}$ & $\begin{array}{l}\text { Odds ratio } \\
(95 \% \mathrm{Cl})^{*}\end{array}$ & $p$ value \\
\hline In-hospital case fatality & $542(11 \%)$ & $1034(15 \%)$ & $0.78(0.64-0.95)$ & 0.016 \\
\hline Long-term mortality & $1363(28 \%)$ & $2382(36 \%)$ & $0.79(0.68-0.91)$ & 0.001 \\
\hline Death or disability & $2611(53 \%)$ & $4112(62 \%)$ & $0.81(0.72-0.91)$ & 0.0001 \\
\hline Not living at home & $1743(35 \%)$ & $2829(3 \%)$ & $0.85(0.74-0.97)$ & 0.019 \\
\hline \multicolumn{5}{|c|}{$\begin{array}{l}\text { *Adjusted by age, sex, time from stroke onset, intracranial haemorrhages, atrial fibrillation, and unconsciousness, and } \\
\text { clustered at the hospital level. }\end{array}$} \\
\hline
\end{tabular}




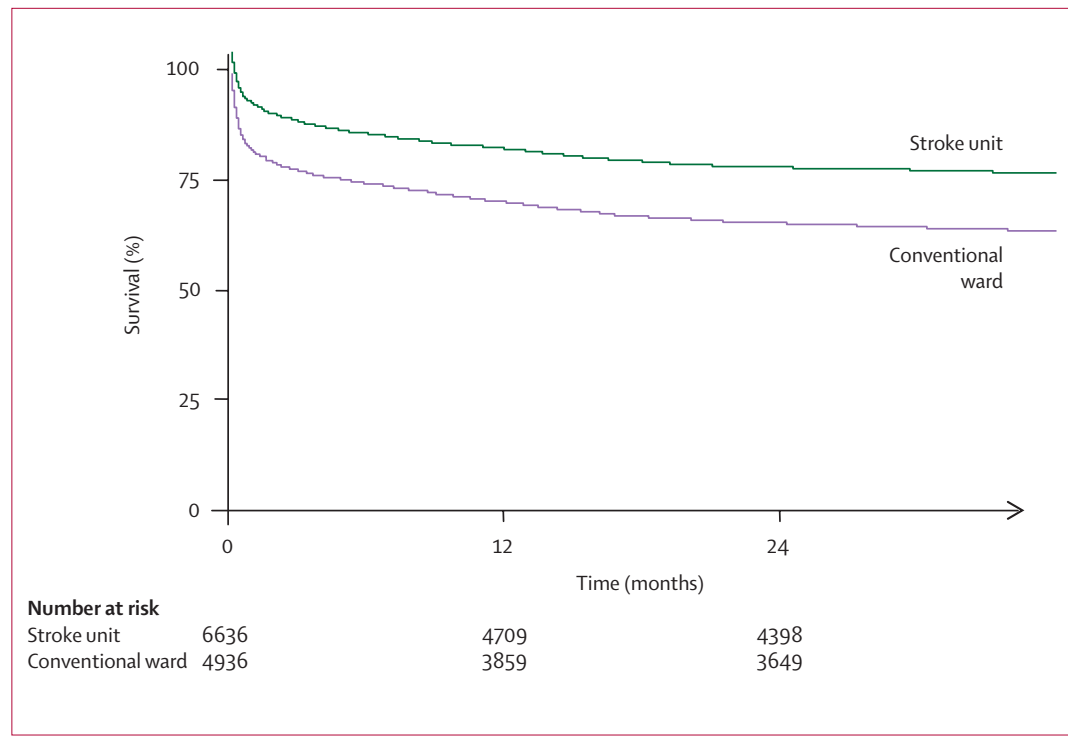

Figure 2: Survival curves for patients admitted to stroke unit or conventional ward

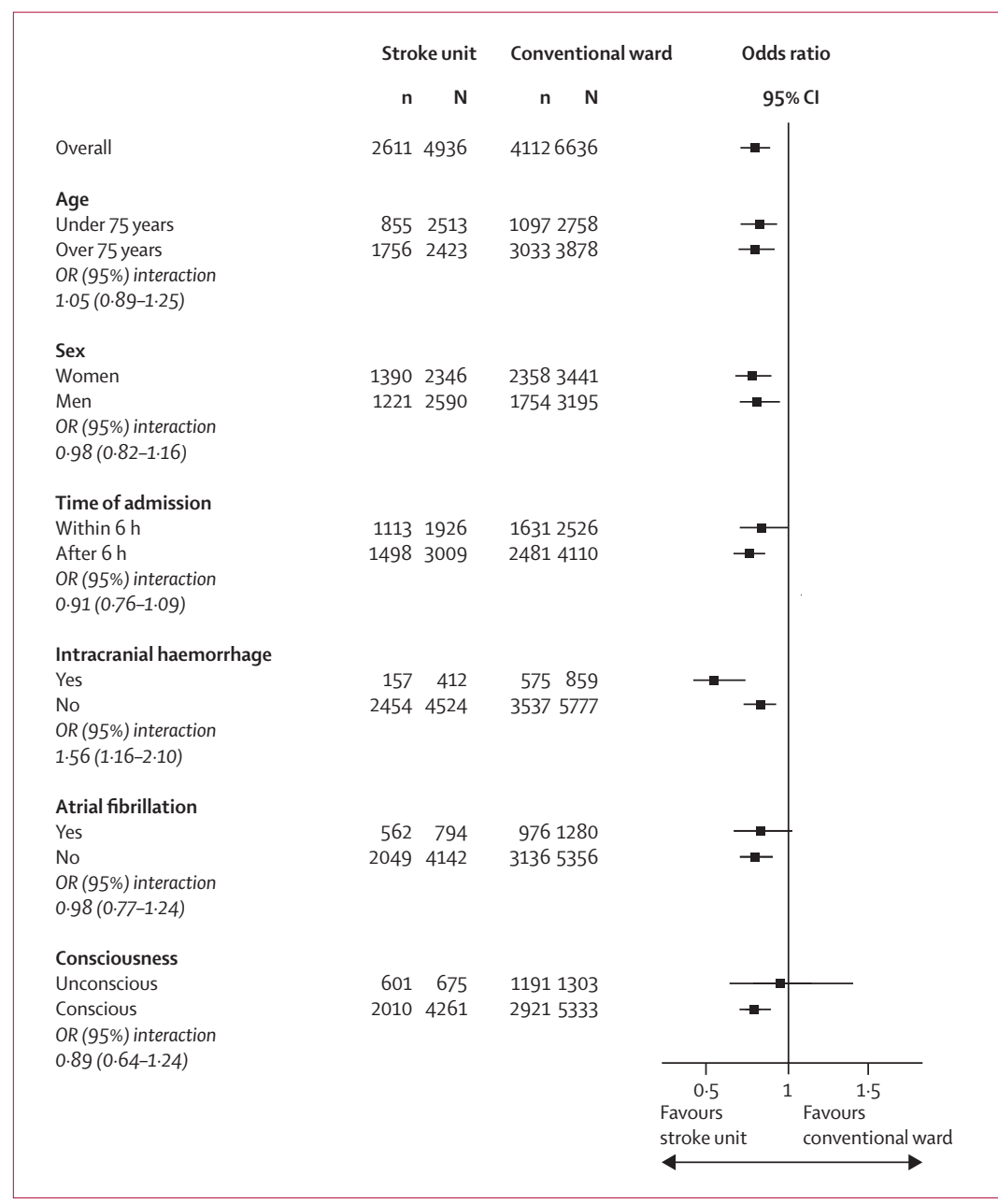

Figure 3: Effect of stroke unit care on death or disability by patient subgroups

Data adjusted for patient characteristics and clustered at the hospital level. significantly higher than of controls (hazard ratio $0 \cdot 86$, $0 \cdot 77-0 \cdot 97 ; p=0 \cdot 0001$; figure 2). The difference in survival between the two groups was most pronounced during the first month after admission (figure 2).

Stroke-unit care was associated with a reduction in the likelihood of death or disability for all subgroups of patients. There were no significant interactions between patient characteristics and the effect of stroke-unit care, with the exception of patients with intracranial haemorrhage, who did better if cared for in a stroke-unit ward (figure 3).

None of the 19 elements of setting, organisation, and processes of care in stroke units changed the probability of the patient being dead or disabled by the end of followup, except for MRI scan availability $24 \mathrm{~h}$ a day, 7 days a week. Patients admitted to a conventional ward had a better outcome if the ward beds were neurological and belonged to an academic hospital (figure 4).

\section{Discussion}

This observational follow-up study, done in the clinical environment in Italy on a large sample of patients with acute stroke, shows that there is an association between stroke-unit care provided in the acute phase of the disease and improvement of stroke outcome. In this setting, stroke-unit care could reduce in-hospital case fatality and also increase the proportion of patients living independently about 2 years after discharge. The possible benefit is maintained over time and is evident both for patients aged less than 75 years and for those over 75 years.

Our results are in agreement with those of a metaanalysis of 23 randomised controlled trials on about 5000 participants. ${ }^{1}$ We also provide evidence that acute stroke-unit care (ie, admitting patients within $48 \mathrm{~h}$ of stroke onset) could improve the patients' outcome. Other evidence for this effect is scarce, despite the fact that most new stroke units had been organised for the care of very acute patients. In fact, 13 systematic reviews of this area of research included participants within 7 days of stroke onset, nine included patients after 7 days, and only one trial enrolled patients within $24 \mathrm{~h}$ of stroke. This small trial was unable alone to show any benefit for stroke-unit care (OR 0.94, 95\% CI $0 \cdot 67-1 \cdot 33$ ). ${ }^{13}$

The design of our study did not allow a random, concealed assignment of patients to the two treatment modalities, and the apparent benefits for stroke-unit care could be due to selection bias and incomplete adjustment for patient characteristics. However, our findings are lent support by several factors. First, the directors and staff of the stroke units and conventional wards studied here were unaware of the ongoing trial when they admitted and treated the enrolled patients, which should reduce selection and performance bias. Second, all major known outcome predictors that had an unbalanced distribution between the two treatment groups were included in the logistic regression analysis. The analysis model had a high goodness-of-fit, and the inclusion of other, less relevant 
predictors would not have modified the final analysis result substantially (Hosmer-Lemeshow $\chi^{2}$ 4.90; df 10; $\mathrm{p}>0 \cdot 7678)$. Third, the analysis that compared outcomes of patients admitted to hospitals with stroke units to those admitted to hospitals without stroke units confirmed the benefit of treatment in a stroke unit. Such intra-hospital analysis should restrict the error due to in-hospital selection bias. Some uncertainty of the validity of our results still remains due to the non-randomised nature of this study. However, to do a randomised trial would be impossible for ethical reasons. Moreover, assessment of outcome in our study was prospective and masked, and less than $3 \%$ of patients were lost to follow-up. Additionally, the analysis was clustered at the hospital level to account for service variability. Furthermore, the inclusion of a large sample of stroke patients means that our findings should have a good level of generalisability.

Other non-randomised prospective studies that aimed to assess the effect of stroke-unit care have produced conflicting results. The Swedish Riks-Stroke studies ${ }^{14,15}$ suggest that stroke-unit care is favourable only for less severe patients, whereas the UK national stroke audit ${ }^{16}$ showed that stroke-unit care substantially reduced inhospital case fatality, and the US Brain Attack Coalition study ${ }^{17}$ did not show any short-term benefit of treatment in a stroke unit. Differences in study design could explain, in part, the differing results. Both the UK and US studies considered short-term outcomes; the effects of stroke-unit care seem to be more apparent after long-term follow-up, as we have shown here. ${ }^{1,18}$ However, higher standards of care for stroke in the conventional-ward groups in previous studies could have reduced their ability to identify differences in outcomes compared with stroke units. In fact, more than $70 \%$ of hospitals included in these three studies had an organised stroke unit. ${ }^{15-17}$ The presence of a stroke unit probably provides a general stimulus for stroke management, influencing the quality of stroke care even in wards with no formal stroke-unit organisation. By contrast, only $12 \%$ of hospitals in the seven Italian regions studied here provided stroke-unit care.

To be able to accurately predict which patients will gain most from stroke-unit care could be important, not just because of restricted resources, but also to aid individual patients to get the most appropriate access. Some policymakers suggest the use of pragmatically restricted admission policies. However, this study, in accordance with other evidence, lends support to the view that there is no firm evidence for restricting access according to patient characteristics - ie, age, sex, blood pressure, etc. ${ }^{1,19}$ Previous reports, ${ }^{1,14}$ together with our results, indicate restricted use of stroke-unit care for patients with mild stroke. However, a larger sample of unconscious patients would be necessary to confirm this finding.

We aimed to identify the key components of an effective acute stroke service. In view of the emergent evidence that a stroke unit with a minimum of dedicated beds and a dedicated staff is effective, a key goal was to determine

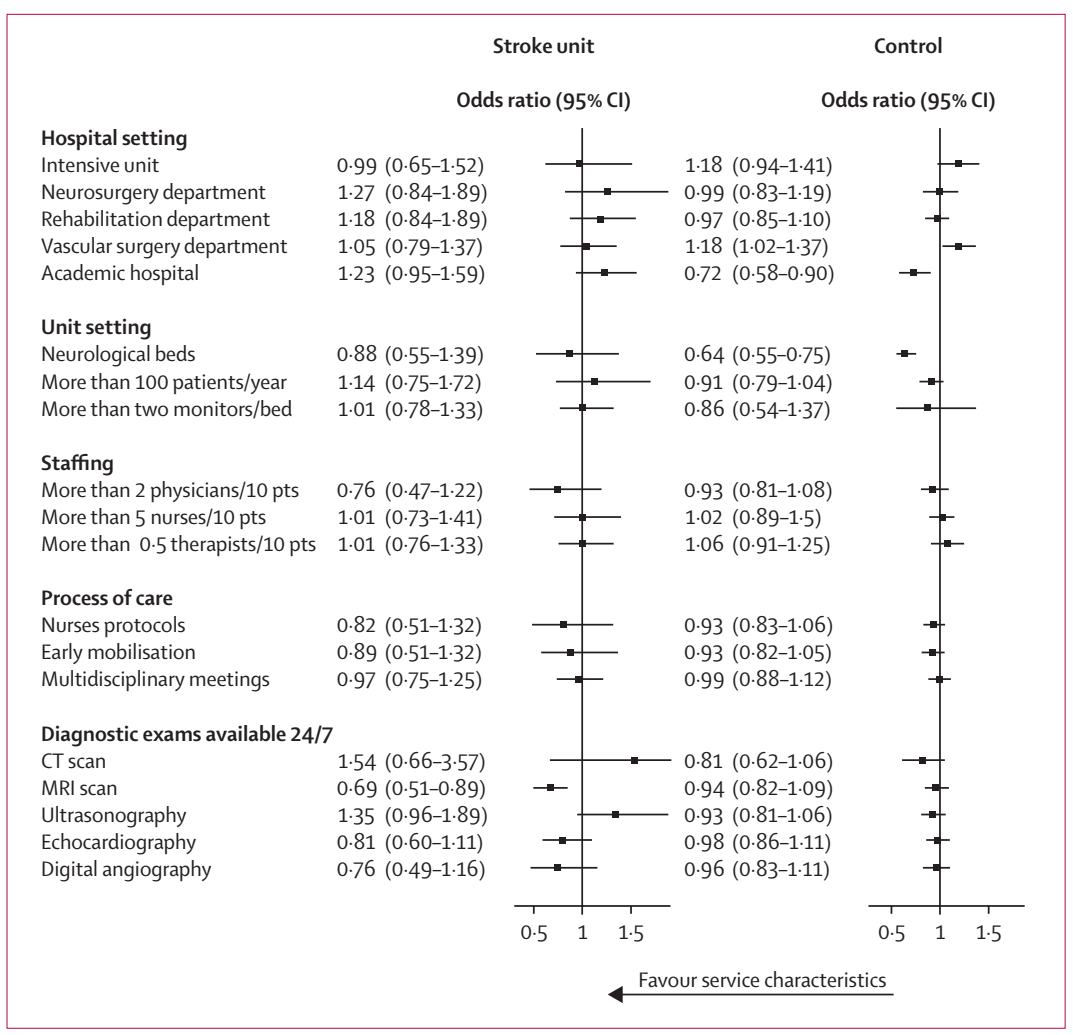

Figure 4: Effect of service characteristics on death or disability

Stroke unit and control services were analysed separately. Data adjusted for patient and unit characteristics and clustered at the hospital level.

exactly what other components of those services could be crucial for achieving better outcomes. That we showed that none of the major stroke-unit elements of care was independently associated with a better outcome is unsurprising. However, caution is needed when interpreting subgroup analyses, especially since only a small number of outcome events were observed, which restricted the statistical power. Nonetheless, our findings are in line with those of the Brain Attack Coalition study, ${ }^{17}$ which used a similar multifactorial analysis, and in part with those of the SCOPES study, ${ }^{20}$ which recorded only a slight association between the probability of being discharged and complete adherence to 15 process-of-care rules. Other studies considered either only the association between elements of care with a stroke unit ${ }^{15,21-23}$ or the effect on outcome of separate elements such as presence of a continuous monitoring system ${ }^{24,25}$ or the practice of early rehabilitation. ${ }^{26}$ The effectiveness of a single element of care could be determined only by doing a large randomised controlled trial in which the other elements do not change during the experiment, which would be very difficult. Nevertheless, the overall effectiveness of stroke-unit care could also be attributed to non-measurable factors-eg, the enthusiasm, motivation, and specialisation of staff-which cannot be attributed to a single individual element separately. 
In conclusion, this study, which used a broad but reliable definition of stroke-unit models on the basis of the use of beds and staff dedicated exclusively to stroke patients, indicates that, provided admission occurs within $48 \mathrm{~h}$ of onset, patients with acute stroke should be treated in stroke-unit wards with dedicated beds and staff, irrespective of age. At present, there is no indication that any further element of care is of benefit. This simple organisation of services is easy to implement, with great benefit in terms of reduced mortality and disability.

\section{PROSIT study group}

Coordinating Center-L Candelise (Ospedale Maggiore Policlinico IRCCS, Milano), G Micieli (IRCCS Fondazione Istituto Neurologico C Mondino, Pavia), R Sterzi (SC Neurologia, Ospedale Niguarda Ca'Granda, Milano, M Gattinoni Ospedale Maggiore Policlinico IRCCS, Milano).

Steering Committee — L Candelise (Ospedale Maggiore Policlinico IRCCS, Milano), M Amigoni (Regione Lombardia, Direzione Generale Sanità), G Micieli (IRCCS Fondazione Istituto Neurologico C Mondino, Pavia), R Sterzi (SC Neurologia, Ospedale Niguarda Ca'Granda, Milano), V Toso (Divisione Neurologica, ULSS 06 Veneto, Vicenza), C Argentino (Dipartimento Scienze Neurologiche, Università La Sapienza, Roma).

Regional Supervisors-Lombardia: G Micieli (IRCCS Fondazione Istituti Neurologico C Mondino di Pavia), I Santilli (Ospedale Niguarda Ca'Granda di Milano), M Stramba-Badiale (Istituto Auxologico Italiano Ospedale San Luca IRCCS di Milano), G P Anzola (Clinica Neurologica Ospedale Sant'Orsola Fatebenefratelli di Brescia). Veneto: V Toso (ULSS 06 Veneto Ospedale Civile San Bortolo di Vicenza Regione Veneto). Friuli Venezia Giulia: F Chiodo (Grandi Azienda Ospedaliera Ospedali Riuniti di Trieste). Liguria: M Del Sette (Dipartimento di Scienze NeurologicheUniversità di Genova Emilia). Romagna: D Guidetti (Azienda Ospedaliera di Reggio Emilia). Toscana: P Nencini (Azienda Ospedaliera Ospedale Careggi di Firenze). Lazio: C Argentino (Policlinico Umberto I Università La Sapienza di Roma). Researchers who did the ward audit-M. Alecci, S Cesi, F Chiodo Grandi, A Cramaro, E Montinaro, E Morandi, M Orsenigo, A Pisanello, M Sommavilla, A Sugo, L Tancredi, E Zambrelli, P Zavarise. Clinicians who gathered data from clinical records-A Bersano, C Agosti, A M Basile, E Biagioni, S Cesi, P Ferrari, S Mantovani, M Orsenigo, S Nappini, A Poggesi, N Reale, A Rocchetto, C Sarti, L Tancredi, A Tegani, A Tinti, P Tosi, V Vergani.

Assessors of patient follow-up-H Aabid, A Argentino, E Ballabio, G Bellatorre, S Borsa, P Bulgarelli, A Cattaneo, I Fabietti, L Facoetti, D Gambaretti, M Groppo, E Impellizzeri, I Limosani, M Limardo, S Lucarelli, D Messina, A Moriggia, E Moro, F Ortolano, G Rossetti, P Stradiotti, V Tosca, P Tosi, R Virgilio.

Advisory board-W Hache (Department of Neurology University Hospital of Heidelberg, Germany), K Asplund (Department of Medicine University Hospital of Umea, Sweden), P Langhorne (Academic Section of Geriatric Medicine Royal Infirmary of Glasgow, UK).

Statistical adviser-A Morabito (Cattedra di Statistica Medica, Facoltà di Medicina e Chirurgia, Università degli Studi di Milano, Milano).

\section{PROSIT collaborating hospitals}

Lombardia-Varese Ospedale di Circolo (VA), Busto Arsizio (VA), Gallarate (VA), Saronno (VA), Somma Lombardo (VA), Tradate (VA), Angera (VA), Como Ospedale S Anna (CO), Como Ospedale G. Valduce (CO), Cantù (CO), Mariano Comense (CO), Erba (CO), Gravedona (CO), Lecco Ospedale A Manzoni (LC), Lecco Ospedale di Circolo (LC), Merate (LC), Sondrio (SO), Sondalo (SO), Milano Ospedale Fatebenefratelli (MI), Milano Ospedale Niguarda (MI), Milano Ospedale S Carlo (MI), Milano Ospedale S Paolo (MI), Milano Ospedale L Sacco (MI), Milano Ospedale Maggiore (MI), Milano Istituto C Besta (MI), Milano S Raffaele (MI), Milano Auxologico (MI), Monza Ospedale S Gerardo (MI), Sesto San Giovanni (MI), Cinisello Balsamo (MI), Garbagnate Milanese (MI), Desio (MI), Carate Brianza (MI), Melzo (MI), Vizzolo Predabissi (MI), Rho (MI), Magenta (MI), Abbiategrasso (MI), Vaprio d'Adda (MI), Vimercate (MI), Giussano
(MI), Cernusco Sul Naviglio(MI), Milano Santa Rita (MI), Milano Villa Turro (MI), San Donato Milanese (MI), Legnano (MI), Lodi (LO), Codogno (LO), Bergamo Ospedali Riuniti (BG), Treviglio (BG), San Giovanni Bianco (BG), Alzano Lombardo (BG), Clusone (BG), Lovere (BG), Romano di Lombardia (BG), Seriate (BG), Osio Sotto (BG), Ponte San Pietro (BG), San Pellegrino Terme (BG), Brescia Spedali Civili (BS), Brescia Ospedale S Orsola (BS), Desenzano del Garda (BS), Gavardo (BS), Leno (BS), Montichiari (BS), Gardone Val Trompia (BS), Iseo (BS), Chiari (BS), Manerbio (BS), Esine ( BS), Gussago (BS), Pavia Istituto C. Mondino (PV), Pavia Ospedale S. Matteo (PV), Broni (PV), Mede (PV), Vigevano (PV), Voghera (PV), Mortara (PV), Cremona (CR), Crema (CR), Casalmaggiore (CR), Mantova Ospedale C Poma $(\mathrm{MN})$, Asola (MN), Suzzara (MN), Pieve di Coriano (MN), Castiglione delle Stiviere (MN). Liguria-Savona(SV), Albenga (SV), Pietra Ligure (SV), Genova Ospedale Galliera (GE), Genova Ospedale P Micone (GE), Genova Villa Scassi (GE), Genova Ospedale S Martino (GE), Lavagna (GE), La Spezia (SP), Sarzana (SP), Imperia(IM),Sanremo (IM), Bordighera (IM). Veneto—Verona Ospedale Civile (VR), Verona Ospedale Policlinico (VR), Legnago (VR), Villafranca (VR), Peschiera del Garda (VR), Negrar (VR), Vicenza (VI), Arzignano (VI), Bassano del Grappa (VI), Noventa Vicentina (VI), Schio (VI), Thiene (VI), Valdagno (VI), Belluno (BL), Feltre (BL), Pieve di Cadore (BL), Treviso(TV), Castelfranco Veneto (TV), Montebelluna (TV), Oderzo (TV), Venezia (VE), Dolo (VE), Mirano (VE), Mestre-Venezia (VE), Portogruaro (VE), San Donà di Piave (VE,) Jesolo (VE), Padova Azienda Ospedaliera (PD), Padova Presidio Geriatrico (PD), Camposampiero (PD), Monselice (PD), Cittadella (PD, Abano Terme (PD), Rovigo (RO), Adria (RO), Porto Viro (RO), Trecenta (RO). Friuli Venezia GiuliaTrieste Ospedale di Cattinara(TS), Trieste Ospedale Santorio(TS), Udine (UD), Gemona del Friuli (UD), Latisana (UD), Palmanova (UD), S Daniele del Friuli (UD), Tolmezzo (UD), Gorizia (GO), Monfalcone (GO), Pordenone (PN), S Vito al Tagliamento (PN), Spilimbergo (PN). Emilia Romagna-Piacenza (PC), Castel San Giovanni (PC), Fiorenzuola D'Arda (PC), Parma Stuard (PR), Parma (PR), Fidenza (PR), Reggio Emilia (RE), Guastalla (RE), Castelnuovo Ne' Monti (RE), Modena Policlinico (MO), Modena Ospedale Civile (MO), Carpi (MO), Castelfranco Emilia (MO), Sassuolo (MO), Bologna Policlinico (BO), Bologna Ospedale S Orsola (BO), Bologna Ospedale Maggiore (BO), Bazzano (BO), Porretta Terme (BO), Imola (BO), Budrio (BO), Bentivoglio (BO), S Giovanni in Persicelo (BO), Ferrara (FE), Cento (FE), Argenta (FE), Comacchio(FE), Copparo (FE), Ravenna (RA), Lugo di Ravenna (RA), Faenza (RA), Forli' (FO), Forlimpopoli (FO), Cesena Ospedale Bufalini (FO), Cesena C C Malatesta (FO), Cesena C C S Lorenzino (FO), Rimini (RN), Cattolica (RN), Riccione (RN). Toscana-Carrara (MS), Massa (MS), Fivizzano (MS), Pontremoli (MS), Lucca (LU), Castelnuovo di Garfagnana (LU), Barga(LU), Pietrasanta (LU), Viareggio (LU), Seravezza (LU), Pistoia (PT), Pescia (PT), Pontedera (PI), S Miniato (PI), Cecina (LI), Livorno (LI), Piombino (LI), Portoferraio (LI), Siena (SI), Poggibonsi (SI), Montepulciano (SI), Bibbiena (AR), San Sepolcro (AR), Cortona (AR), Arezzo (AR), S Giovanni Valdarno (AR), Montevarchi (AR), Massa Marittima (GR), Obetello (GR), Grosseto (GR), Pisa (PI), Firenze Ospedale Nuovo (FI), Firenze Ospedale S Maria (FI), Firenze Ospedale Careggi (FI), Borgo S Lorenzo (FI, Prato (FI), Bagno a Ripoli (FI), Figline Valdarno (FI), Castelfiorentino (FI), Empoli (FI). Lazio-Viterbo (VT), Acquapendente (VT), Civita Castellana (VT), Montefiscone (VT), Ronciglione (VT), Tarquinia (VT), Magliano Sabina (VT), Rieti(RI), Roma Ospedale S Giacomo (RM), Roma Ospedale CTO (RM), Roma Ospedale Giovan Battista Grassi (RM), Roma Ospedale S Eugenio (RM), Roma Ospedale Fatebenefratelli S Pietro (RM), Roma Ospedale Fatebenefratelli S Giovanni (RM), Roma Ospedale S Carlo (RM), Roma Ospedale Israelitico (RM), Roma C C Villa Aurora (RM), Roma Life Hospital (RM), Roma Ospedale S Camillo (RM), Roma Ospedale S Giovanni (RM), Roma Ospedale S Filippo (RM), Roma Ospedale S Pertini (RM), Roma Ospedale Policlinico (RM), Genzano di Roma (RM), Anzio (RM), Albano Laziale (RM), Civitavecchia (RM), Colleferro (RM), Frascati (RM), Marino (RM), Monterotondo (RM), Subiaco (RM), Tivoli (RM), Velletri (RM), Bracciano (RM), Palombara Sabina (RM), Valmontone (RM), Pomezia (RM), Latina (LT), Formia (LT), Aprilia (LT), Frosinone (FR), Alatri (FR), Anagni (FR), Ceccano (FR), Pontecorvo (FR), Sora (FR), Cassino (FR). 


\section{Contributors}

L Candelise contributed to the design of the study, coordination, data collection and management, statistical analysis, interpretation of the results, and writing of the manuscript. M Gattinoni contributed to coordination, data collection and management, statistical analysis, and writing of the manuscript. A Bersano participated in the coordination, data collection and management, interpretation of the results, and writing of the manuscript. G Micieli took part in the design of the study, coordination, interpretation of the results, and writing of the manuscript. R Sterzi contributed to the design of the study, coordination, interpretation of the results, and writing of the manuscript. A. Morabito contributed to the design of the study, and statistical aspects. All authors saw and approved the final version of the manuscript.

\section{Conflict of interest statement}

We declare that we have no conflict of interest.

\section{Acknowledgments}

We thank the directors and the administrative staff of the hospitals and the participating wards' directors for their useful collaboration.

\section{References}

1 Stroke Unit Trialists' Collaboration. Organised inpatient (stroke unit) care for stroke. Cochrane Database Syst Rev 2001; 3: CD000197.

2 Brainin M, Bornstein N, Boysen G, Demarin V. Acute neurological stroke care in Europe: results of the European Stroke care inventory. Eur J Neurol 2000; 7: 5-10.

3 Roine RO, Kaste M. Published guidelines : updates and synthesis. In: Bogousslavsky K, ed. Acute stroke treatment, 2nd edn. London: Martin Dumitz, 2003; 261-68.

4 Alberts MJ, Latchaw RE, Selman WR, et al. Recommendations for comprehensive stroke centers. A consensus statement from Brain Attack Coalition. Stroke 2005; 36: 1597-618.

5 Norrving B. Organised stroke care. The core of effective stroke care provision. Stroke 2005; 36: 1616-18.

6 Candelise L, Micieli G, Sterzi R, Morabito A, on behalf of the PROSIT collaborators. Stroke unit and general wards in seven Italian regions: the PROSIT study. Neurol Sci 2005; 26: 81-94.

7 Spolaore P, Brocco S, Fedeli U, et al. Measuring accuracy of discharge diagnoses for a region-wide surveillance of hospitalized strokes. Stroke 2005; 36: 1031-34.

8 Sterzi R, Micieli G, Candelise L, on behalf of the PROSIT collaborators. Assessment of regional acute stroke unit care in Italy: the PROSIT study. Cerebrovasc Dis 2003; 15 (suppl 1): 16-18.

9 van Swieten JC, Koudstaal PJ, Visser MC, Schouten HJ, van Gijn J. Interobserver agreement for assessment of handicap in stroke patients. Stroke 1998; 19: 604-07.

10 Candelise L, Pinardi G, Aritzu E, Musicco M. Telephone interview for stroke outcome assessment. Cerebrovasc Dis 1994; 4: 341-43.
11 Hayes RJ, Bennett S. Simple sample size calculation for clusterrandomized trials. Int J Epidemiol 1999; 28: 319-26.

12 Kerry SM, Bland JM. The intracluster correlation coefficient in cluster randomisation. BMJ 1998; 316: 1455-60.

13 Ronning OM, Guldvog B. Stroke units versus general medical wards. II: neurological deficits and activities of daily living: a quasirandomised controlled trial. Stroke 1998; 29: 586-90.

14 Stegmayr B, Asplund K, Hulter-Asperg K, et al. Stroke units in their natural habitat. Can results of randomized trials be reproduced in routine clinical practice? Stroke 1999; 30: 709-14.

15 Glader EL, Stegmayer B, Johansson L, Hulter-Asberg K, Wester PO. Differences in long-term outcome between patients treated in stroke units and in general wards. A 2-year follow-up of stroke patients in Sweden. Stroke 2001; 32: 2114-30.

16 Rudd AG, Hoffman A, Irwin P, Lowe D, Pearson MG. Stroke unit care and outcome. Results from the 2001 National Sentinel Audit of Stoke (England, Wales, and Northern Ireland). Stroke 2005; 36: 103-06.

17 Douglas VC, Tong DC, Gillum LA, et al. Do the Brain Attack Coalition's criteria for stroke centers improve care for ischemic stroke? Neurology 2005; 64: 422-27.

18 Indredavik B, Bakke F, Slordahl SA, Rokseth R, Haheim LI. Stroke unit treatment: 10 year follow-up. Stroke 1999; 30: 1524-27.

19 Kaste M, Palomaki H, Sarna S. Where and how should elderly stroke patients be treated. A randomised trial. Stroke 1995; 26: 249-53.

20 Cadilhac DA, Ibrahim J, Pearce DC, et al. Multicenter comparison of processes of care between stroke units and conventional care wards in Australia. Stroke 2004; 35: 1035-40.

21 Evans A, Perez I, Harraf F, et al. Can differences in management processes explain different outcomes between stroke unit and stroke-team care? Lancet 2001; 358: 1582-92.

22 Dennis M. Stroke services: the good, the bad and the... J R Coll Physicians Lond 2000; 34: 92-96.

23 Kapral MK, Laupacis A, Phillips SJ, et al. Stroke care delivery in institutions participating in the Registry of the Canadian Stroke Network. Stroke 2004; 35: 1756-62.

24 Sulter G, Elting JW, Langedijk M, Maurits NM, De Keyser J. Admitting acute ischemic stroke patients to a stroke care monitoring unit versus a conventional stroke unit. A randomised pilot study. Stroke 2003; 34: 101-04.

25 Cavallini A, Micieli G, Marcheselli S, Quaglini S. Role of monitoring in management of acute ischemic stroke patients. Stroke 2003; 34: 1-5.

26 Indredavik B, Bakke F, Slordhal SA, Rokseth R, Haheim LL. Treatment in combined acute and rehabilitation stroke unit: which aspects are most important? Stroke 1999; 30: 917-23. 